\title{
Escrever-se, fotografar-se: convergências entre Vivian Maier e Ana Cristina Cesar
}

1 Bacharel em Letras pela Universidade de São Paulo (USP), mestranda do Programa de Pós-graduação em Teoria Literária e Literatura Comparada da Universidade de Sáo Paulo (USP), com o projeto No meio do reflexo: um estudo comparado entre Vivian Maier e Ana Cristina Cesar", com apoio da Nivel Superior - Brasil (CAPES). COT.

E-mit: julaizumino@gmail.com

Recebido em: $15 / 2 / 2019$.

Aprovado em: 13/6/2019.

Endereço:

Cidade Universitária, São Paulo, SP, CEP: 05508-900.
To write oneself, to photograph oneself: convergences between Vivian Maier and Ana Cristina Cesar

Julia Pasinato Izumino

Universidade de São Paulo, Faculdade de Filosofia, Letras e Ciências Humanas, Programa de Pós-graduação em Teoria e Literatura Comparada, São Paulo, SP, Brasil.

\section{RESUMO}

Procurando desenvolver uma análise das afinidades eletivas entre a Fotografia e a Poesia (NAVAS, 2017), atentamos para as convergências e divergências mapeáveis entre os autorretratos fotográficos da estadunidense Vivian Maier e a poesia mista de prosa, diário e correspondência íntima da brasileira Ana Cristina Cesar, buscando compreender como se dão os procedimentos de construção do sujeito ficcional trabalhados dentro da própria lógica dos gêneros autobiográficos e autorrepresentativos. Neste artigo, analisando especificamente a forma como ambas as artistas incorporam os gestos criativos - isto é, a encenação do ato de escrever e do ato de fotografar - aos seus textos e imagens, os mecanismos de interlocução e figuração do Outro e de seus próprios corpos.

Palavras-chave: Poesia. Fotografia. Autorretratos. Sujeito Ficcional.

\section{ABSTRACT}

In an effort to develop an analysis of the "elective affinities between Photography and Poetry" (NAVAS, 2017), we look at the recognizable convergences and divergences drawn between the photographic self-portraits of Vivian Maier and the poetry by Ana Cristina Cesar. We seek to understand how the construction of fictional subjects is performed within the very logic of the autobiographical and self-representational genres. In this article, we will analyse specifically how both Maier and Cesar incorporate the creative gestures - that is, the act of writing and the act of photographing - to their texts and images; the mechanisms of interlocution and figuration of the Other and their bodies.

Keywords: Poetry. Photography. Self-portrait. Fictional subject. 


\section{Fotografar-se}

"Assim, por distorção, por deslocamento, fotografia e poesia transbordam as coordenadas da imagem, da linguagem, hiperbolizam as aparências".

(Adolfo Montejo Navas)

"Percebo que o seu segredo é que, ao dizer "eu", este texto realiza a conjunção entre o real (esta minha vida ou quem a viva), o simbólico (este discurso ou o pronome eu que aqui deliro) e o imaginário (este ouvir constante da minha própria biografia)".

(Ana Cristina Cesar)

Entre a imensa ${ }^{2}$ produção fotográfica de Vivian Maier, encontramos uma quantidade considerável de autorretratos. Se, por um lado, o ato de voltar a própria câmera para si é corrente (DUBOIS, 1994; MEDEIROS, 2000) - e podemos inclusive nos recordar de fotógrafos que se consagram com obras constituídas praticamente de autorretratos, como Samuel Fosso, Cindy Sherman, Francesca Woodman, John Coplans, para nomear alguns - a produção específica de Maier chama a atenção pela insistência na busca pela figuração não propriamente de seu rosto ou corpo, mas de seu reflexo, sombra e silhueta. Diferentemente de fotógrafos - inclusive os mencionados acima - que se colocam diante de suas câmeras e, com a ajuda de terceiros ou artifícios técnicos (disparadores remotos, timers), constroem retratos de si, escamoteando o aparelho, trazendo em primeiro plano a encenação, a pose do sujeito fotografado, deixando reverberar em segundo plano o caráter propriamente produtivo do fazer fotográfico, a ação de acionar o obturador 3 , Maier

2 Sabemos ainda relativamente pouco da biografia desta fotógrafa, cuja obra foi "descoberta" postumamente. Ela nasceu em Nova Iorque em 1926, começou a fotografar em 1951 e, além do seu emprego como babá, quase até a sua morte, em 2009, produziu uma coleção de aproximadamente 150 mil fotografias e slides (entre negativos, poucas ampliações feitas por ela mesma e, em sua maioria, rolos não revelados), e centenas de vídeos $8 \mathrm{~mm}$. Pamela Bannos (2017) nota que, como a sua obra foi inicialmente vendida em leilões e então revendida por vendedores independentes em antiquários, mercados de fotografia vintage e sites (como o eBay), a totalidade do espólio foi dispersada em uma extensão que não conseguimos mensurar. Os números que temos hoje são incertos (e, dadas as circunstâncias, talvez nunca chegaremos a uma contagem precisa), mas se apoiam nos dados, rolos fotográficos e impressões que temos mapeados e identificados até hoje. (para mais informações ver BANNOS, 2017)

Comentando os autorretratos na pintura Renascentista, James Hall diria que: "A ausência das mãos e do equipamento do pintor pode quase sugerir uma imagem miraculosa, pintada sem a atuação humana" se fotografa no mais das vezes com a câmera na mão, incorporando a máquina no enquadramento e no instante de seu próprio registro.

Na equação que se estabelece então entre o ser fotógrafo e o ser fotografado, ao se retratar Maier parece buscar o equilíbrio através da transparência do ato fotográfico. Mas, consequências desta escolha, mais do que simplesmente estética ou estilística, repercutem nos modos de leitura que esta fotografia, já tão curiosa, nos oferece.

Se dissemos anteriormente que Vivian Maier é apresentada hoje na crítica como uma prolixa fotógrafa de rua - apesar da difícil definição $0^{4}$ dessa prática - se torna oportuno começar esta análise com um autorretrato que, enredado pelo acaso, mistura-se com as circunstâncias de uma fotografia de rua.
(HALL, 2014, p. 43, tradução nossa). Na fotografia, imagem técnica por excelência, o caráter "miraculoso" que menciona Hall poderia ser então substituído por uma impressão de objetividade "pura".

Enquanto Susan Sontag (1980) a definiria guiada por uma atitude que compreendia, em um só tempo denúncia e crítica social e uma tentativa de possuir e paralisar os lampejos da vida urbana antes que se alterassem ou desaparecessem, para a documentação da vida cotidiana e promoção de uma reforma estética a favor da ressignificação e o embelezamento do prosaico e do pequeno, Abigail Solomon-Godeau, extremamente crítica da prática, que considera antiética por majoritariamente se apoiar no registro de sujeitos alheios sem o seu consentimento, argumenta que a fotografia de rua se consolida como um gênero da fotografia - se é que os há - no final do século XX, quando surge a necessidade da História da Arte estabelecer uma historiografia que legitimasse a prática e os artistas individuais que nela perseveraram. Foi então formulada, como ela diz, “...para excluir, ou talvez reprimir, a maioria esmagadora das fotografias, dos anos 1840 para frente, que retratam espaços urbanos com ou sem pedestres. Em suma, o que veio a ser conhecido como fotografia de rua é uma noção mais ou menos artística - ou, talvez pode-se dizer "auterística" - dessa atividade (SOLOMON-GODOEAU, 2017, p. 79, tradução nossa). 
Figura 1 - Self-Portrait 1955

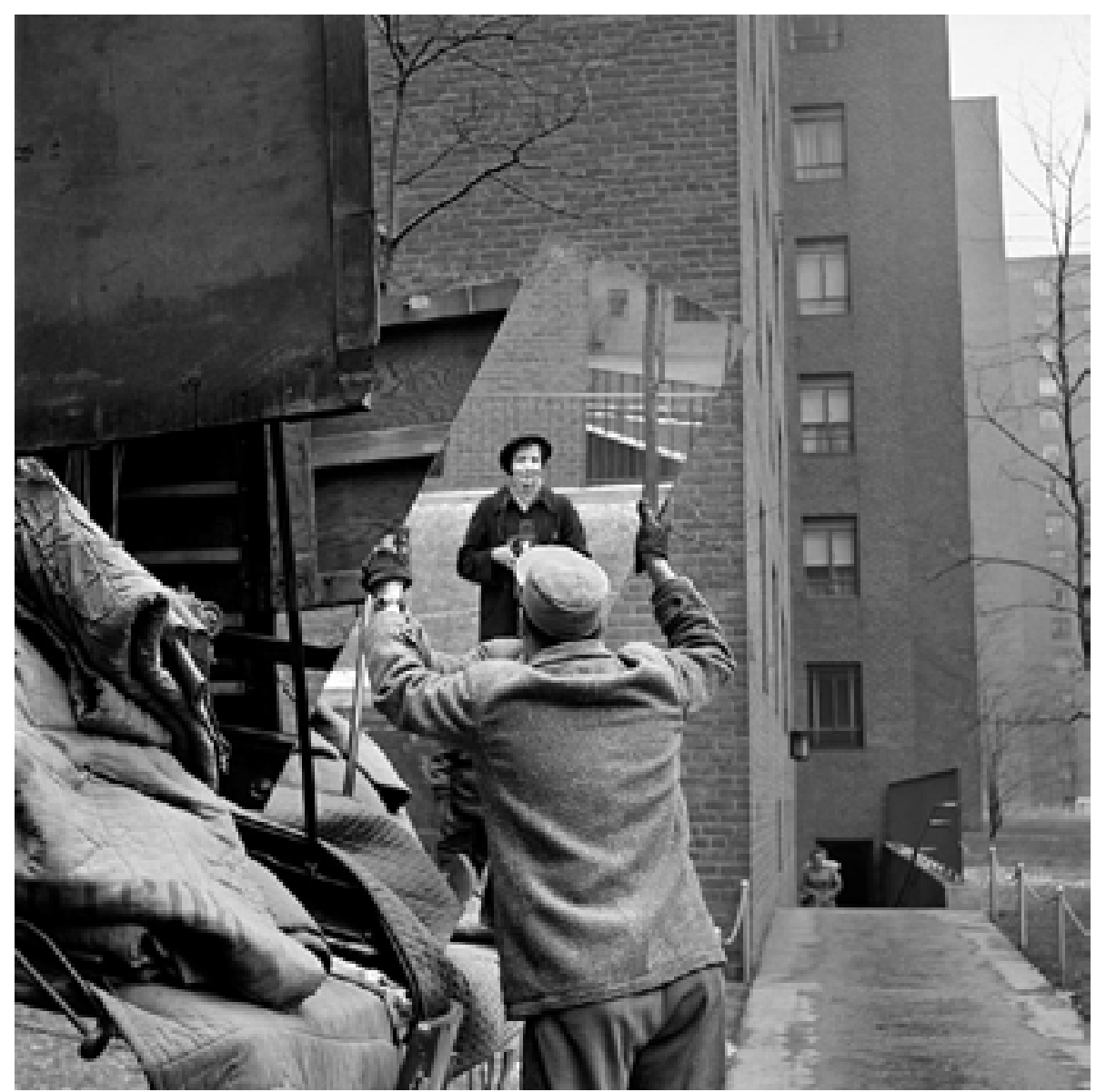

Fonte: Estate of Vivian Maier, Maloof Collection 5 .

Self-Portrait, 1955 VM1955W03420-05-MC. Reprodução/Captura de imagem realizada do site http:// www.vivianmaier.com/. Disponível em: http://www.vivianmaier.com/gallery/self-portraits/\#slide-13. Acesso em: 5 set. 2019
No retrato da Figura 1 de um homem tirando um espelho de um carreto irrompe a figura da fotógrafa que, intrusa no cotidiano do outro, eterniza com a sua câmera (à mostra) o momento-síntese deste encontro ocasional.

No primeiro plano, o homem perfeitamente centralizado, de costas para a fotógrafa, segura o espelho. A nossa visão de seu rosto é bloqueada pela posição de sua cabeça e, assim, no espelho que nos oferece, não vemos o seu reflexo: vemos, sim, Vivian Maier segurando a sua máquina, olhando a sua imagem, bem para a altura dos próprios olhos.

A verticalidade predominante na imagem cria um padrão simétrico que parece emoldurar a cena, entre a linha dos prédios, as árvores, as portas do carreto, a mulher que sobe a escada, os braços erguidos do homem, até a costura centralizada no tecido de sua boina e de seu casaco. Na imagem virtual do espelho, a mesma verticalidade se repete: os prédios, a cerca, as árvores e a fotógrafa. A única coisa que de fato foge dessa simetria é o próprio espelho, o objeto cuja ponta superior inclinada indica exatamente o eixo central do quadro, colocando-o em lugar de destaque no enquadramento e, justamente, ironicamente, quebrando com a organicidade do resto. 0 encontro entre as imagens do corpo do homem e do reflexo da fotógrafa ocupa perfeitamente o quadrante central e evidencia um jogo fortuito de contrastes: o claro/escuro de suas roupas; a imagem do rosto dela, claro e em evidência, enquanto dele se vê o torso todo, de costas; os braços abaixados da fotógrafa que assim opera a sua câmera e os braços erguidos do homem que assim descarrega o carreto... E então notamos que, apesar do olho do observador primeiramente procurar, e finalmente repousar, no rosto de Maier no reflexo, o ponto focal da lente está mirado na boina do homem, poucos milímetros abaixo. Ela, que raras vezes se olha de frente enquanto fotografa a própria imagem, aqui se encara e até sorri - mas, fora de foco. Embora nos mostre seu rosto, não nos permite livre acesso - nos oferece apenas a fotografia de um reflexo, em segundo plano, desfocada. Como é a ela que procuramos - pois, como nos lembra Susan Sontag (1980), a vontade do espectador diante de um retrato é ver quem esteve diante da câmera, ver as pessoas "como elas nunca se veem, ao ter delas um conhecimento que elas nunca podem ter; transforma as pessoas em objetos que podem ser simbolicamente possuídos" (SONTAG, 1980, p. 25), revelando aquilo que apenas uma lente objetiva consegue captar - obriga nosso olho a repousar no embaçado, deslocado, descentralizado. 
Existe uma dimensão da representação do sujeito diante de si que Philippe Dubois considera intradiegética, isto é, estabelece uma duplicidade no gesto de observação deste sujeito que, ao mesmo tempo que vê a imagem de si, se vê sendo visto, tal qual Narciso diante de seu reflexo:

O face a face que o olhar para si no espelho implica está nesse nível totalmente amarrado nele mesmo, fechado sobre os dois protagonistas diegéticos que são Narciso e seu reflexo. Nós, espectadores, estamos excluídos dessa relação, fora do jogo, obscenos. Somos um terceiro termo ignorado, neutro; estamos posicionados num "ele" voyeur do casal "eu"/tu". Somos mantidos à distância (icônica) de sua relação de conexão (indiciária) (DUBOIS, 2004, p. 143).

De certa forma também excluídos da diegese desse autorretrato de Maier, temos nossa entrada vetada ao entendimento completo da fotografia - não vemos o rosto do homem, não conhecemos as circunstâncias desse evento uma vez que "uma foto não é apenas o resultado de um encontro entre um evento e um fotógrafo; tirar fotos é um evento em si mesmo" (SONTAG, 1980, p. 21) - não sabemos nem se a foto foi tirada por acaso ou montada por Maier, que pediu ou comandou a pose do carregador.

Ainda entre as centenas de retratos que produziu, são recorrentes as fotografias de pessoas dormindo em lugares públicos e pessoas captadas desapercebidas, de costas ou de distâncias bem curtas. Maier, que um dia teria respondido "eu sou um tipo de espiã" a um estranho ${ }^{6}$ que teria perguntado sobre a sua profissão - revelando um pouco de seu ofício e de seu senso de humor - parecia encarar quase como um jogo o gesto de aproximação do outro, de chegar o mais perto possível sem ser percebida, propositalmente interferindo com o seu corpo a privacidade e o espaço pessoal do sujeito retratado.

6 Barry Wallis, o estranho em questão, conta a anedota em entrevista a John Maloof para o documentário Finding Vivian Maier (2014).
Figura 2 - Self-Portrait 1971

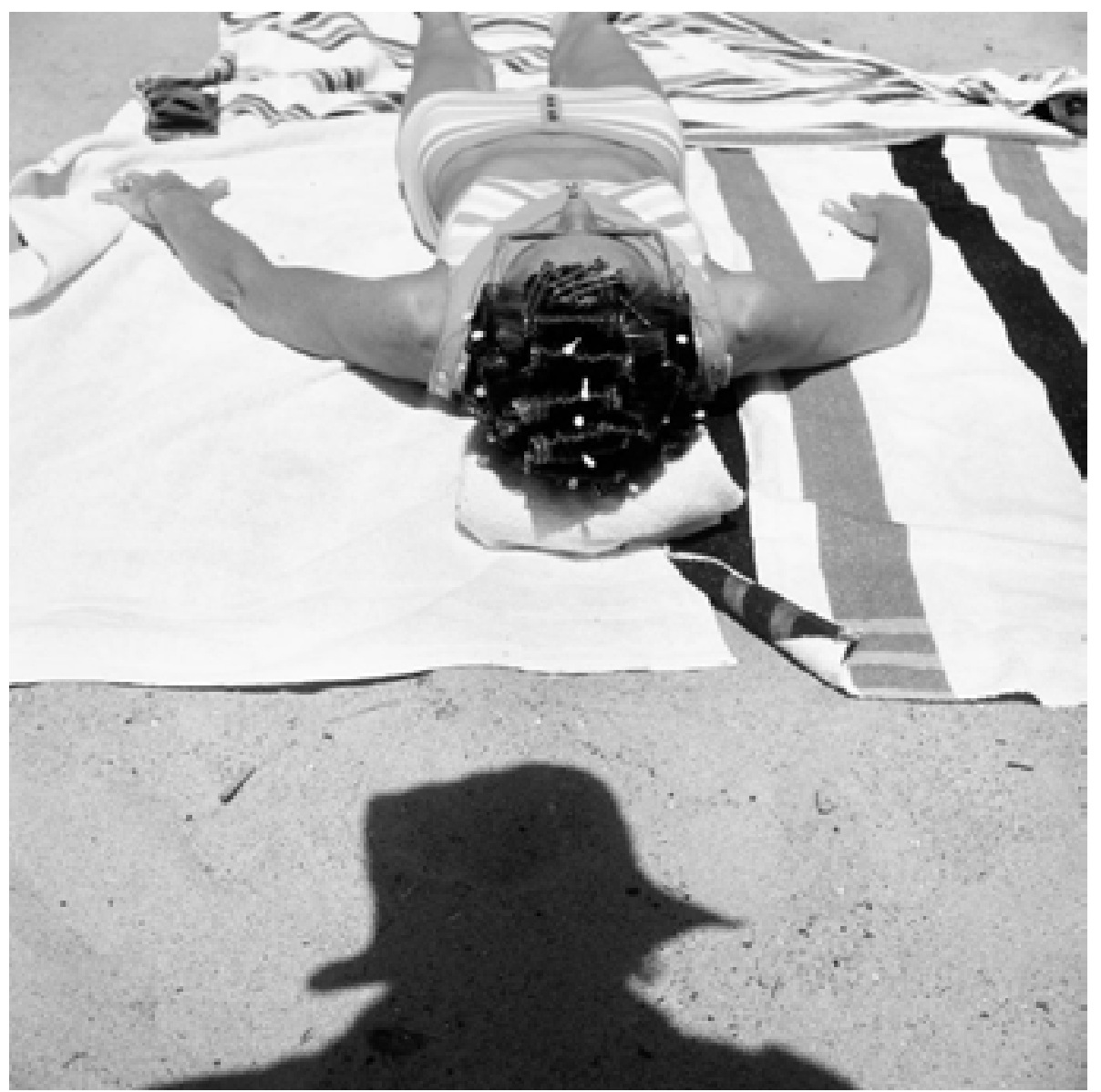

Fonte: Estate of Vivian Maier, Maloof Collection?

Self-Portrait, 1971. VM1971W01758-10-MC. Reprodução/Captura de imagem realizada do site http:// www.vivianmaier.com/. Disponível em: http://www.vivianmaier.com/gallery/self-portraits/\#slide-37. Acesso em: 5 set. 2019 . 
Na fotografia "Self-portrait 1971" (Figura 2), tal jogo fica evidente. 0 ângulo quase vertical do enquadramento nos indica que Maier deve ter se abaixado para ficar quase na mesma altura da mulher que, inadvertidamente, dorme da praia. Como o homem que tirava o espelho do carreto, a banhista aqui tem o seu rosto oculto pela inclinação da câmera e, sem poder ser identificada, participa colateralmente desse autorretrato ${ }^{8}$. Inclinando levemente a câmera, Maier capta a silhueta da sombra de sua própria cabeça a meros centímetros da outra (em uma escolha deliberada, nos parece, posto que para tanto acaba até por cortar do quadro os pés da mulher), intrometendo-se no retrato que rouba de outra pessoa.

Mas, se deixarmos um pouco de lado os procedimentos técnicos da produção dessa fotografia, é a figuração dos corpos e dos sujeitos e, particularmente, a posição tomada pela fotógrafa que nos chama a atenção. Se na fotografia anterior os demais elementos formais do enquadramento apontam todos para o seu reflexo, que queda porém um pouco desfocado e descentralizado, aqui, a substituição de seu rosto pela sua silhueta nos coloca diante de uma ambiguidade latente: por um lado, a escolha por incluir a sua sombra, indicial, rastro da sua presença, evidencia o exercício físico e dêitico de se colocar nessa posição, naquele "aqui e agora", para conseguir a imagem; por outro, a silhueta anônima, genérica, coloca a fotógrafa necessariamente do lado de trás da câmera, onde não a vemos, e acaba produzindo uma ausência, o registro da falta do corpo material da fotógrafa na sua imagem.

No seu próprio retrato, então, a fotógrafa não se encontra. E somos tanto convidados quanto impelidos a ocupar o seu lugar diante do quadro - nosso olhar assume a posição da objetiva, a alguns centímetros do chão e da mulher que não conseguimos identificar, e nos encontramos referencialmente no mesmo lugar que a fotógrafa pode ter ocupado no momento em que produziu a imagem. A repetição do tema do retrato da sua sombra ou de seu reflexo no espelho parece provocar na produção de Vivian Maier a construção de um sujeito específico, esse que cria subterfúgios formais para se dissolver no próprio ato de representar-se. Como vemos neste retrato (Figura 3) no qual, no interior de um quarto, entre a desordem da intimidade alheia, Maier se coloca centralizada no reflexo do espelho:

A escolha por categorizar esta imagem como um "autorretrato" é da curadoria da The Vivian Maier Foundation, verificável no site oficial dedicado à divulgação de sua obra. Pelas próprias condições da publicação póstuma das fotografias, sabemos que Maier não teve posição nas escolhas curatoriais ou mesmo organizacionais de seu espólio. Neste artigo, a decisão por manter esta fotografia junto à análise como um autorretrato vem de uma vontade de tensionar justamente os limites de tal categoria.
Figura 3 - Self-Portrait Undated

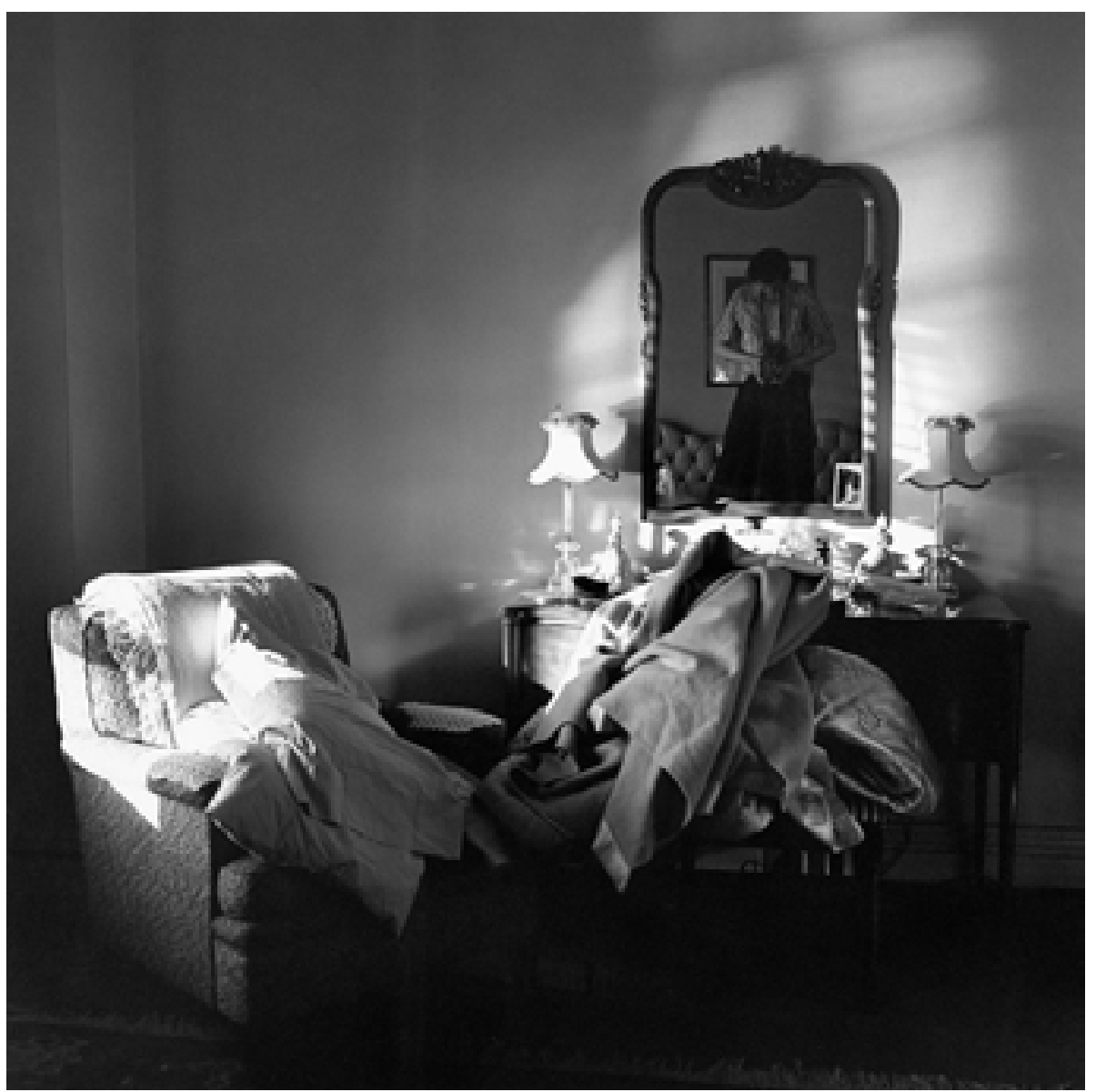

Fonte: Estate of Vivian Maier, Maloof Collection ${ }^{9}$

Self-Portrait, Undated VM19XXW03129-02-MC. Reprodução/Captura de imagem realizada do site http://www.vivianmaier.com/. Disponível em http://www.vivianmaiercom/gallery/self-portraits/\#slide-22. Acesso em: 5 set. 2019. 
De cabeça baixa, olha para o visor de sua Rolleiflex; os ombros encolhidos e os braços levemente dobrados correspondem à postura de uma fotógrafa em atividade. Aqui, a fotógrafa, o único sujeito aparente, transforma-se em pura imagem ao ocupar unicamente o espelho. Essa impressão se agrava com o fato de a distância duplicada pela ótica no espelho fazer do seu reflexo um dos elementos mais distantes do ponto de vista do observador. Por ter a cabeça abaixada e negar mostrar seu rosto, parece procurar se esconder no ato que produz a evidência material - a imagem fotográfica - de que ela esteve ali, confirmando, mais uma vez, a vontade de negar sua presença.

Segundo Roland Barthes (1980), o retrato fotográfico criaria a objetividade do eu como outro, a transformação da materialidade do corpo em imagem. 0 sujeito que se vê sendo fotografado sente a perda do domínio de si e de seu corpo para aquele que opera a câmera. Isso implica e forja no eu um novo tipo de comportamento - a pose, simulacro do eu, que traduz uma tentativa de retomar o domínio sobre a imagem que se vai fazer:

Graças a ela [a pose] o sujeito torna-se um modelo; deixa-se captar como uma forma entre outras formas, ao interagir com um cenário que lhe confere uma identidade retórica quando não fictícia, fruto de uma ideia de composição plástica e social a um só tempo (FABRIS, 2004, p. 58).

Fazer autorretratos diante do espelho tem, porém, uma especificidade, de acordo com Dubois, que encontrou na sua gênese "a dissolução total do sujeito pelo e no ato fotográfico. Imagem-ato" (DUBOIS, 1994, p. 19).

Existem, então, duas imagens e duas temporalidades. Há o espelho que oferece uma representação sempre direta, que remete ao "aqui-agora" em curso, ao presente singular de quem está se olhando (se vendo sendo visto). E há a foto, sempre adiada, que remete a uma anterioridade a qual foi detida, congelada em seu tempo e seu lugar:

Pegar esse instante de total presença para si mesmo, captá-lo, registrá-lo, passa-lo para a película, é iniciar o processo que decerto fará o autorretrato existir, erigirá a efígie, instalará a autocontemplação no tempo imóvel da fotografia, mas é, ao mesmo tempo, condenar a relação imediata consigo mesmo, é destiná-la a estar sempre acabada, é começar a fazer desaparecer na imagem e sob a mesma" (DUBOIS, 2011, p. 16).
Absorvido pelo ato fotográfico, o sujeito que habita o espelho abre um campo de visibilidade neste quadro que nos lembra, por analogia, o que Michel Foucault considera sobre o quadro "Las Meninas", de Diego Velázquez:

Na pintura holandesa, era tradição que os espelhos desempenhassem um papel de reduplicação: repetiam o que era dado uma primeira vez no quadro, mas no interior de um espaço irreal, modificado, estreitado, recurvo. Ali se via a mesma coisa que na primeira instância do quadro, porém decomposta e recomposta segundo uma outra lei. Aqui o espelho nada diz do que já foi dito. [...].

Ora, ele não faz ver nada do que o próprio quadro representa. Seu olhar imóvel vai captar à frente do quadro, nessa região necessariamente invisível que forma sua face exterior, as personagens que ali estão dispostas. Em vez de girar em torno de objetos visíveis, esse espelho atravessa todo o campo da representação, negligenciando o que aí poderia captar e restitui a visibilidade ao que permanece fora de todo olhar. Mas essa invisibilidade que ele supera não é a do oculto: não contorna o obstáculo, não desvia a perspectiva, endereça-se ao que é invisível ao mesmo tempo pela estrutura do quadro e por sua existência como pintura. [...]

0 espelho assegura uma metátese da visibilidade que incide ao mesmo tempo sobre o espaço representado no quadro e sua natureza de representação; faz ver, no centro da tela, aquilo que, do quadro, é duas vezes necessariamente invisível (FOUCAULT, 2007, p. 9-10).

Ao registrar o momento em que se torna reflexo no espelho, Maier funda a distância da imagem virtual ao mesmo tempo que se retira do enquadramento. Como no retrato de sua sombra, não é o seu corpo que se mostra aqui, mas sim o rastro de sua presença que, no entanto, no nosso presente de observação, já não está. 0 que observamos é o sujeito que cria a figuração de seu próprio desaparecimento.

Curiosamente, é justamente dessa posição desconfortável que o retrato de Vivian Maier nos lembra da poesia de Ana Cristina Cesar, apesar da distância que separa as artistas - Ana Cristina é natural do Rio de Janeiro e Maier nasceu e viveu em Nova Iorque e, mais tarde, Chicago - e dos motivos que temos para acreditar que as duas não se conheceram pessoalmente ou a obra uma da outra - posto que a poesia de Ana Cristina não havia sido traduzida para o inglês à época e o 
espólio de Maier só veio à luz em 2010, depois da morte de ambas. Na tentativa de nos aproximarmos mais da questão das confluências e divergências estruturais ${ }^{10}$ entre a Fotografia e a Poesia, acompanhando as formulações de Adolfo Montejo Navas (2017), que compreende que ambas as artes têm como ponto de contato "uma tríade operacional" - tempo, forma, imagem - que opera em conjunto para fazer das imagens fotográficas e poéticas internamente concentradas, intensas, metonímicas, parece-nos especialmente curioso observar como, na obra das duas artistas, os procedimentos formais e elementos temáticos explorados em cada prática parecem resultar na construção de sujeitos ficcionais análogos, tensos, ambíguos e autoirônicos, que se constroem formalmente no texto e na imagem de tal maneira a colocar em questão o próprio gênero que produzem.

\section{Escrever-se}

Ana Cristina Cesar costuma ser colocada pela crítica ao lado dos seus contemporâneos poetas da chamada geração marginal. A atenção voltada ao "imediato agora" da experiência particular - contra o otimismo perdido de um Futuro utópico, progressivo linear, ou um resgate de tradições e mitos de origem - é, como compreende Heloísa Buarque de Hollanda (2004), uma das grandes marcas dessa geração ${ }^{11}$. Intensificado até suas últimas consequências, o imediatismo do registro e a incorporação quase total da vida à arte almejaria alcançar a poetização da experiência, até que chegue o dia "quando tudo o que eu diga/ seja poesia", lembrando a famosa exortação de Paulo Leminski (2013, p. 77).

10 Acompanhamos aqui a compreensão de Kenneth Reinhard, que procura entender na literatura comparada: "um modo de leitura lógica e eticamente anterior à similitude, uma leitura em que textos não são agrupados em "famílias" definidas por semelhança e diferença, mas sim em "vizinhanças" determinadas por contiguidade acidental, isolamento genealógico e encontro ético", seguindo "o princípio e a prática da literatura comparada em que a junção de textos ou discursos se baseia não apenas em congruências históricas, isomorfismos estruturais ou contradições dialéticas, mas também no ato crítico através do qual um texto toma o lugar ou se "vizinha" de outro" (REINHARD, 1995, p. 785-786, tradução nossa)

${ }_{11}$ Acompanhando, como observa Octávio Paz, uma tendência contemporânea no Ocidente: "Agora, na segunda metade do século XX, aparecem certos sinais que indicam uma mudança em nosso sistema de crenças. A concepção da história como processo linear progressivo se mostrou inconsistente. Essa crença nasceu com a idade moderna e, de certo modo, foi sua justificação, sua raison d'être. Sua ruptura revela uma fratura no próprio seio da consciência contemporânea: a modernidade começa a perder a fé em si mesma" (PAZ, 2013, p. 155).
Na poesia que parece querer se sustentar "na corda bamba" entre Arte e Vida, a valorização da experiência e da expressão do sujeito se manifesta, sobretudo, no registro surpreendido e quase espontâneo do cotidiano vivido pelo poeta. Ainda, neste contexto específico de produção, este texto poético parece almejar uma relação de cumplicidade com o leitor que circularia nos mesmos espaços e compartilharia as mesmas referências, factualmente vivendo quase o mesmo cotidiano. Nesse esforço pelo diálogo através da literatura, a blague, a conversa, o tom de segredo e o registro íntimo na forma do diário se somam aos acontecimentos menores e banais do dia a dia e se tornam matéria privilegiada. Ainda, tomadas de assalto, a captura imediata e quase sem depuração de cenas, conversas alheias e sensações faz com que essa poesia se assemelhe a uma coleção de snapshots:

A poesia brasileira que no Modernismo apelou para a Kodak para descobrir os instantâneos da vida, hoje realiza o poema-polaroide, de revelação instantânea e "elabora" um estilo e uma estética do inacabado, do "surpreendido" pelo acaso da interferência do poeta (FREITAS, 2005, p. 113).

No limite, no entanto, a gana pela poetização total da vida acaba também se dobrando sobre o próprio processo da escrita - o momento específico em que o acontecimento é capturado, retirado do tempo cronológico e a experiência efêmera se paralisa na palavra:

O poema traça uma linha divisória que separa o instante privilegiado da corrente temporal: nesse aqui e nesse agora principia algo [...]. Esse instante é ungido com uma luz especial: foi consagrado pela poesia, no melhor sentido da palavra consagração (PAZ, 2012, p. 53).

Autoconscientes, o ato da escrita e a sua materialidade se tornam tema corrente na poesia da geração marginal, seja notando a leveza do encontro fortuito com a palavra, como neste poema de Chacal:

Anatomia

pego a palavra no ar 
no pulo paro

vejo aparo burilo

no papel reparo

e sigo compondo o verso

(CHACAL, 2007, p. 181).

cujo título já aponta para a vontade do olhar para as partes constitutivas do corpo do poema, as palavras pegas por acaso "no pulo" e "no ar" por um sujeito oculto em primeira pessoa que, como nota Flora Süssekind (2004), institui um ego omnipotente que centraliza e organiza a experiência com rapidez e fluidez, expresso no ritmo acelerado dos versos curtos, sem pontuação, e com a aliteração dos pês - pego, palavra, pulo, paro, aparo, papel, reparo, compondo - que marca um ritmo de caminhada do poeta que segue em frente, compondo versos. Seja como na obra de Ana C., de um momento um pouco posterior da poesia marginal - posto que tem a sua estreia em livro já na virada para a década de 1980, com Cenas de Abril (1979) - em que o ato da escrita surge de maneira multifacetada, polivalente e, no mais das vezes, acompanhando o que nos parece certo reconhecer como uma "aflição da escrita".

Se há diversos momentos desta poética de Cesar, como já reconheceu e analisou Viviana Bosi, em que o eu lírico se encontra em diferentes meios de transporte, sejam carros, ônibus, trens, navios, "Escrevendo no automóvel", como declara logo o primeiro verso de "Fogo do Final" (CESAR, 2013, p. 121), dirigindo a mil ou na contramão - afinal: "Não, a poesia não pode esperar./ $\mathrm{O}$ brigue toca as terras geladas do extremo sul./ Escapo no automóvel aos guinchos." (CESAR, 2013, p. 284) - então “[o] próprio ato de escrever é figurado em deslocamento, como se a poesia fosse uma viagem veloz no tempo e no espaço: "Estou sirgando, mas/ o velame foge"” (BOSI, 2013, p. 429). De vez em quando, ainda, neste trânsito, a poesia parece conseguir se emancipar da poeta, guiar a sua própria ambulância - que saía de "sirenes baixas,/ recolhendo os restos das conversas,/ das senhoras,/ 'para que nada se perca/ ou se esqueça'” (CESAR, 2013, p. 235) - ou fugir, correr para a outra direção, como neste trecho de "Contagem Regressiva":
Tenho medo de ter deixado a máquina ligada

elétrica IBM lebre louca solta pelo campo

Corri atrás

da lebre louca em corrida coerente

atrás das tocas e escrevi: trejeitos (CESAR, 2013, p. 274).

Esta "corrida coerente" da poeta atrás de sua máquina de escrever selvagem aponta para aquilo que Viviana Bosi compreende como um desejo de comunhão com as palavras, ou a supressão do intervalo que se instaura entre o sujeito e a sua expressão:

Seu ideal seria correr tanto que conseguisse cruzar a linha de chegada junto às palavras, compartilhando com elas a intensidade da reunião improvável entre esse sujeito acicatado pelo moscardo da iminência e sua necessidade de expressão (BOSI, 2015, p. 21).

De maneira contígua, Marcos Siscar encara o deslocamento do sujeito da poesia de Ana Cristina como um movimento em trânsito entre o poema, a vida e o leitor. Isso porque o ato da escrita sempre ${ }^{12}$ tem um destino - melhor dizendo, uma destinação e um destinatário que, mesmo "singular e anônimo" (SANTIAGO, 2013), ainda se impõe no horizonte da escrita e, pela forma específica como é incorporado ao texto de Ana Cristina, obriga o mapeamento dos limites materiais do texto.

Acompanhando as tendências de seus contemporâneos ${ }^{13}$, Ana C. escreveu textos mistos de poesia e prosa em forma de diário e correspondência íntima. Além dos simulacros de entradas de diário que permeiam toda sua produção, dois livros se destacam pelo formato: Correspondência Completa (1979) é uma longa carta que "Júlia" envia para "my dear" e Luvas de Pelica (1980) se organiza como espécie

12 Como a própria autora chegou a declarar em uma fala de 1983: “[...] do ponto de vista de como é que nasce um texto, você, quanto está escrevendo, o impulso básico de escrever é mobilizar alguém, mas você não sabe direito quem é esse alguém" (CESAR, 1999, p. 258).

${ }_{13}$ Como vemos poema de Cenas de Abril: "18 de fevereiro": "Me exercitei muito em escritos burocráticos, cartas de recomendação, anteprojetos, consultas. 0 irremovível trabalho da redação técnica. Somente a dicção nobre poderia a tais alturas consolar-me. Mas não o ritmo seco dos diários que me exigem!” (CESAR, 2013, p. 33) 
de diário de viagem, caderno terapêutico e correspondência íntima. Contudo, consciente da interrupção do diálogo pelo fato da escrita - pois que esta tem, por condição, a retirada de circulação da palavra do mundo, quebrando o vínculo que une o eu que fala para um outro que escuta, ou ainda, o autor de seu leitor (BLANCHOT, 2011) - e da manipulação operada pelo "olhar estetizante" que se interpõe entre a experiência vivida e a poesia, Ana Cristina produz a dramatização da escrita, construindo uma "ambivalência provocante, uma brecha que esvazia a oposição e a hierarquia entre vida e poesia" (SISCAR, 2011, p. 25).

A procura incessante por um você e a espera pela sua resposta impossível por vezes se transformam em tema do poema, por exemplo neste trecho de Luvas de Pelica (1980), que começa com o verso: "Estava no canto do quarto esperando o carteiro soar quando resolvi te escrever mesmo assim", e depois segue:

A folha é muito dura e hoje é o dia mais longo do ano com ou sem você. Thank you very much, thank you very much. A próxima canção que eu vou cantar é Me Myself I (aplausos fortes e breves e mais longos) que neste verão quero dedicar a você que não me escreve mais e é diretamente responsável pelo meu flerte com o homem dos correios. Tonight... maybe one of these days... he wrote a letter about a girl... Are you ready? One, two, three - estou mestre em abrir envelopes (CESAR, 2013, p. 65).

Como nota Maria Lúcia de Barros Camargo (2003), este livro de Ana Cristina deixa sentir uma força de atração muito forte entre a literatura e a biografia, posto que, em 1980, Ana C. de fato estava morando na Inglaterra, onde então fazia uma pós-graduação, e de fato viajou para Paris e para Espanha, lugares e itinerários que aparecem tematizados ao longo dos poemas do livro. Talvez também por isso que as formas do diário íntimo e da correspondência pareçam se fundir e confundir tanto, estabelecendo no poema, na superfície, a busca e a tentativa de comunicação com o outro que nunca se completa. Fica bastante claro, então, o que Siscar considera como a relação provocativa - quer dizer, que tanto seduz quanto irrita - que a poesia de Ana Cristina estabelece com os seus leitores:

O sujeito se constitui e se modula pela relação nervosa com o leitor, ou melhor, com aquilo que, na retórica da interlocução, aponta para um transbordamento do sujeito, do espaço delimitado da subjetividade do próprio poeta. Nesse sentido, a provocação daquilo que se apresenta como sinceridade diz respeito a uma política da alteridade, ao gesto de estabelecer uma relação, algo como um traço ético da subjetividade (SISCAR, 2011, p. 24)

No trecho destacado, o gesto da escrita de uma carta se escamoteia em um espetáculo, fazendo a interlocução variar do âmbito mais privado (a escrita para um sujeito específico e particular) ao mais público (a apresentação /encenação diante de uma plateia). O poema todo constitui, em seus polos, o processo de construção de uma cena enunciativa. Desse modo, um sujeito forja um eu que convoca o leitor, um você anônimo - "que não me escreve mais" - para dentro do texto, no mesmo ato em que o mantém distanciado e impossibilitado de adentrar na cena por subterfúgios formais como as elipses, alusões obscuras, versos partidos, imagens inacabadas e a irrupção de outros escritores - como fica evidente principalmente no parágrafo destacado, em que se monta a situação de espetáculo, anuncia-se uma canção (talvez de Billie Holiday) e interrompe a apresentação em um anticlímax: "Tonight... maybe one of these days... he wrote a letter about a girl... Are you ready? One, two, three - estou mestre em abrir envelopes" (CESAR, 2013, p. 65). Ainda, as perguntas que encerram o texto:

Não estou pegando direito. Por que estão vaiando agora? Você será possível que não avisou que se mudou? Estou escrevendo para a peça vazia, para a louca senhoria, para a locatária com mania? Me desculpe mas isso é uma grande covardia (2013, p. 65)

- procuram a interpelação direta de um interlocutor, evidenciando o que Siscar dizia anteriormente: neste poema que se funda para mobilizar o outro, o chamamento mesmo se torna, por vezes, matéria da poesia e o eu se faz objeto, ferramenta para a interlocução, nascendo já, assim, na iminência da alteridade:

Se escrita da vida (a bio-grafia) designaria, antes, o modo como a vida, ao escrever-se diante de meus olhos, coincidiria com a própria experiência ao estabelecer e evidenciar o uso estético do texto íntimo e confessional que pressupõe uma criação, desentranha-o da vida e o recontextualiza numa exposição dramática. Nesse momento, maravilhada, a poeta vislumbra que "sou eu que sou vivida, sou eu que sou grafada". o paradoxo 
é, então, constituído não somente pela convivência dos opostos, mas também pelos dilemas que resultam da ideia de que, por um lado, escrever é sempre constituir a partir da perda do modelo (da vida) e de que, por outro, viver é sempre dar corpo a uma escrita (aquilo que constitui essa vida) (SISCAR, 2011, p. 30)

\section{Convergências?}

Aqui, a exposição do gesto da escrita se torna fundamental. Como a fotógrafa que se retrata diante do espelho, deixando evidente a câmera e o mecanismo de captura da imagem, o texto de Ana Cristina se dobra sobre si mesmo, escreve que escreve - ou que escrevia, ou que não escreverá mais - e evidencia o seu processo de criação, como que chamando atenção ao suporte material e estético com o qual opera. É ainda assim que também o silêncio e a espera - por uma resposta, um telefonema, um cartão-postal, uma carta -, consequências da dramatização do diálogo em poesia, são substituídos pelo ato da escrita ou pelo paradoxo pragmático da negação em ato (MAINGUENEAU, 2001).

É o que podemos perceber, por exemplo, no poema "meia-noite. 16 de junho", de Cenas de Abril: "Não volto às letras, que doem como uma catástrofe. Não escrevo mais. Não milito mais. Estou no meio da cena, entre quem adoro e quem me adora. [...]" (CESAR, 2013, p. 37), cujo título simula uma entrada de diário e se inicia já com a negação do próprio texto. Ou neste outro poema do mesmo livro, com a mesma data do calendário como título, "16 de junho": "Decido escrever um romance. Personagens: a Grande Escritora de Grandes Olhos Pardos, mulher farpada e apaixonada. 0 fotógrafo feio e fino que me vê pronta e prosa de lápis comprido inventando a ilha perdida do prazer. [...]" (CESAR, 2013, p. 35), em que o gesto da escrita reverbera em camadas profundas de repetição: o eu lírico escreve que decide escrever sobre uma escritora, interrompida, todavia, pela figura de um fotógrafo que se intromete na cena, escrutina e modifica a realidade para a qual aponta a sua câmera, transformando então a escritora em personagem de sua própria fotografia (instaurando uma circularidade ad nauseam na qual a imagem fotográfica representa a escritora no momento mesmo em que escreve que percebe estar sendo observada por um fotógrafo, por sua vez incorporado à poesia também como personagem...).

Já em "Cabeceira", de A teus pés, temos: "Intratável./ Não quero mais pôr poemas no papel/ nem dar a conhecer minha ternura./ Faço ar de dura,/ muito sóbria e dura,/ não pergunto/ "da sombra daquele beijo/ que farei?" (CESAR, 2013, p. 106) que, além de tratar discursivamente do fato da escrita - ou melhor, de novo, da negação da escrita - ainda brinca com a intertextualidade, incorporando um verso de Manuel Bandeira ${ }^{14}$ entre aspas, para não restar dúvidas de que este verso é uma intromissão de outra voz colada nesta cena enunciativa - e adensando o caráter construído do texto de ficção. Diante de tantas negativas ao fato da escrita que surgem na superfície do texto, lembramo-nos dos comentários de Luciana di Leone que, ao pensar as várias imagens de dissolução e desaparição ${ }^{15}$ que surgem ao longo da poética de Ana C., compreende:

No entanto, embora não esteja colocada para o sujeito poético, a tensão entre aparecer e desaparecer existe para nós, leitores. Ela encontra-se, justamente, na convivência do pedido de desaparição e de apagamento de marcas e memórias, junto ao gesto de escrever esse pedido, constituí-lo em marca e testemunho, em poema. 0 sujeito não para de aparecer no pedido de desaparição (LEONI, 2008, p. 51).

Uma citação que, fortuitamente, nos remete diretamente à fotografia de Vivian Maier e os seus modos de exploração de sua própria imagem - ou, melhor, os modos de operar a dissolução de seu corpo em imagem, sombra, rastro.
14 Do poema "Canção" de Lyra dos Cinquent'anos e que, aliás, também tematiza a impossibilidade do contato físico imposta pelo suporte da poesia, começando com a seguinte estrofe: "Mandaste a sombra de um beijo/ Na brancura de um papel:/ Tremi de susto e desejo,/ Beijei chorando o papel" (BANDEIRA, 1987, p. 143). ${ }_{15}$ Poderíamos, por exemplo, lembrar do poema de Inéditos e Dispersos (1985): "Não querida, não é preciso correr assim do que/vivemos. 0 espaço arde. 0 perigo de viver.//Não, esta palavra. 0 encarcerado só sabe que não vai morrer,/ pinta as paredes da cela./ Deixa rastros possíveis, naquele curto espaço./E se sabe que não vai morrer,// pinta as paredes da cela./ Deixa rastros possiveis, naquele curto espaço./E s escapa incólume, a cada minuto./Este é meu testemunho" (CESAR, 2013, p. 311). 
Figura 4- 1976

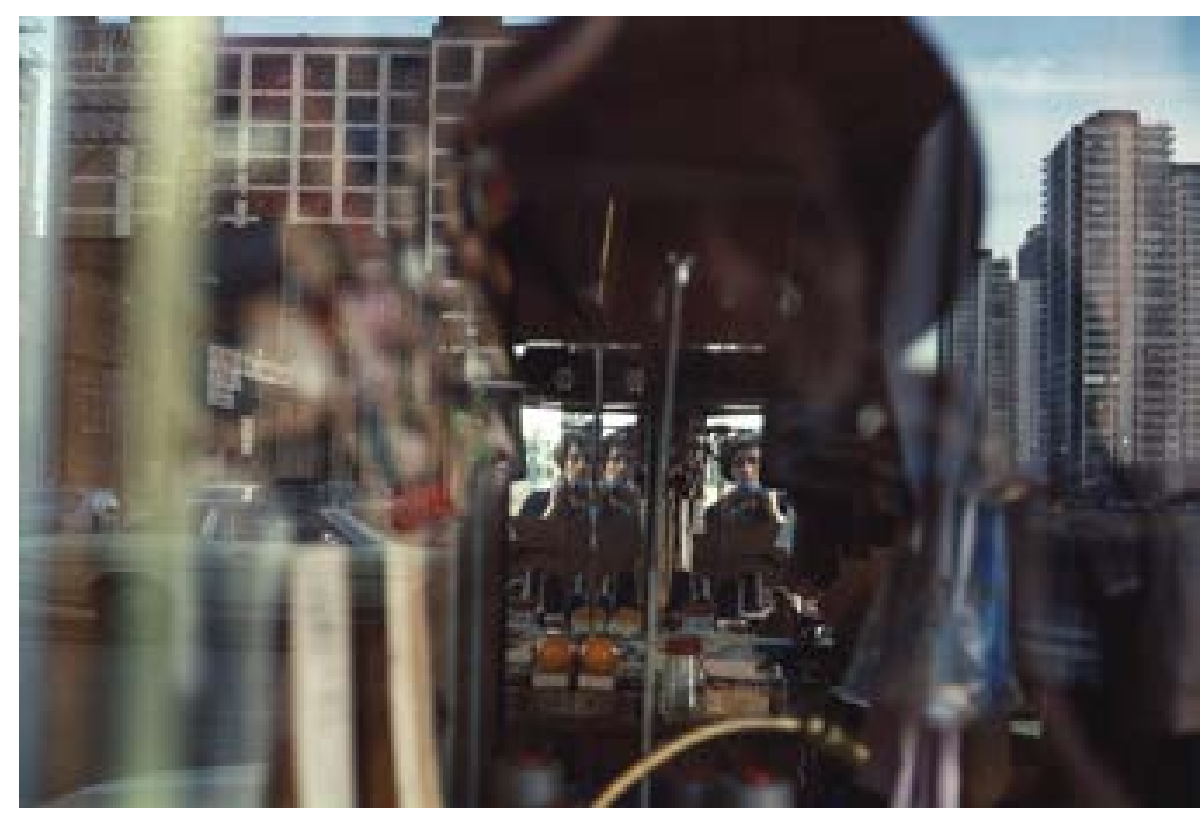

Fonte: Estate of Vivian Maier, Maloof Collection ${ }^{16}$.

Dessa vez abandonando a Rolleiflex ${ }^{17}$, trabalhando com o filme colorido em sua câmera $35 \mathrm{~mm}$, Vivian Maier explora os matizes de cor e sombra. Um pouco curvada para se encaixar no ângulo certo diante da vitrine, provoca uma ilusão de ótica: vemos que surge como um espectro agigantado, escuro, ocupando todo o centro do quadro e proporcionalmente se equiparando aos prédios refletidos à distância; além disso, ainda, por três vezes encara-se de frente com a câmera na altura do queixo, em uma imagem que se repete, no mesmo tamanho e paralelamente, bem no centro do enquadramento. Mesmo que calculadamente ocupando o ponto

1976 VM1976K04621-06-MC. Reprodução/Captura de imagem realizada do site http://www.vivianmaier.com/. Disponível em: http://www.vivianmaier.com/gallery/self-portraits-color/\#slide-7. Acesso em: 5 set. 2019.

17 Como conta Bannos, Maier tinha algumas câmeras diferentes, sabia transitar muito bem entre os vários formatos, o rolo colorido e o preto e branco e "enxergava diferente com cada câmera" (BANNOS, 2017 p. 174, tradução nossa), fazendo escolhas precisas e deliberadas de acordo com qual imagem queria produzir. de maior claridade e definição do quadro, que de restante se compõe com uma mistura de sombras, reflexos e confluências entre o dentro e o fora da vitrine, de novo não encontramos o seu corpo como evidência de uma presença.

O mais interessante desta fotografia é como, em última instância, ela parece operar com a consequência maior do tornar-se espectro de Barthes. Ilusão de ótica, a figura que aparece segurando a câmera está presa entre os ecos dos espelhos, em uma dimensão exatamente no meio dos reflexos, desterritorializada e vazia de corporalidade.

0 que está em jogo, aqui, portanto, é a forma como a evidência do ato fotográfico - o "fotografar-se-fotografando", a simples câmera incorporada ao enquadramento - ajuda Maier a manipular a figuração de seu corpo de maneira a esvaziá-lo enquanto matéria corpórea mesmo. Sombra, reflexo, espectro, o seu corpo se produz no mesmo instante em que se encerra como rastro de uma ação no tempo.

Se poderíamos concordar quando Margarida Medeiros declara - "Ora a fotografia cria, precisamente, uma relação entre o olhar e o corpo - a imagem do corpo - que torna este ilusoriamente presente, e, por conseguinte, ilusoriamente possível" (MEDEIROS, 2000, p. 91) - então, diante do autorretrato de Maier, o desejo, seja de posse ou comunhão, por este sujeito produtor queda interrompido. Isso porque o que haveria de narcísico nessa autorrepresentação, garantindo a dimensão "biografizante" e indicial da fotografia, é rompido pela manipulação formal e a evidência do ato fotográfico:

Eis o fundamento da questão: o narcisismo é o índice, o princípio de uma aderência real do sujeito a si mesmo como representação, em que o sujeito só pode se perder, naufragar - exceto se justamente sair do índice, exceto se cortar essa relação circular e especular de copresença a si mesmo como outro, exceto se renunciar aos dêiticos (o autodiálogo "eu"/"tu") para entrar no narrativo ("ele") (DUBOIS, 2004, p. 146).

Algo que, na poesia de Ana Cristina, se manifesta de forma completamente diferente - na sua poesia, é iminente a relação entre $o$ ato da escrita e as figurações do corpo: "Não o corpo da linguagem nem a linguagem do corpo, mas o corpo na linguagem como lugar entre a voz e o olhar, com todos os dramas que se interpõe quando se interpõe a escrita no circuito do desejo" (ZULAR, 2015, p. 101). 
A aproximação entre a escrita e o corpo se apresenta na obra de Ana Cristina Cesar de diversas maneiras. Se em um momento o exercício da escrita chega a infligir dor - "Datilografei até sentir câimbras" (CESAR, 2013, p. 39), - em outro, só a escrita mecânica da cópia datilógrafa, ao contrário da escrita confessional, é capaz de curar o corpo do prurido: em "Jornal íntimo", também de Cenas de Abril, se lê: "27 de junho:/ o prurido só passou com a datilografia. Copiei trinta páginas de Escola de mulheres no original sem errar" (CESAR, 2013, p. 40). Em outro momento ainda se apresenta pela via do desejo, que pode ser erótico - "Por afrontamento do desejo/ insisto na maldade de escrever" (2013, p. 27) - ou mesmo literário, como nota Annita Costa Malufe:

O texto literário, diz Ana Cristina, seria aquele movido por esse desejo corporal: trata-se no entanto de um desejo propriamente literário. $\mathrm{Ou}$ seja, não um desejo de seu autor, algo de ordem pessoal, mas sim um desejo próprio à natureza do escrito literário. 0 texto poético, literário, o poema: é ele quem deseja e que, de certo modo, concretiza esse desejo ao ser lido. Ao contrário do que afirma Ana C., podemos pensar que, ao ser lido, o texto passa efetivamente a existir enquanto corpo, efetuando seu movimento como o corpo do leitor (MALUFE, 2018, p. 442).

E ainda pela sutil afinidade que surge entre o gesto da escrita e o encontro do sujeito com o seu reflexo:

Minuta de férias

Fraturo as mãos. Me reúno com casal em lugar ermo. Máquina de escrever é peça irônica entre bagagens. "Faz vinte dias não olho no espelho" me diz ela. "Faz vinte dias não escrevo palavra" digo-lhe em revide. Estaríamos a falar da mesma coisa? Enquanto isso eu e ele discutimos a grandeza dos poetas. Entre um Pessoa e outro me aconselha estilo enxuto. Estaria a falar em pouca lágrima? Faço pouca fé. Sem mãos piora essa pessoa. Nem sei onde contar esse triângulo. Manietada a memória não escapa das três extremidades. Nem mão tenho para atirar a flauta seca ao mar. No gesso estéril aqueço mitologias: o casal se encolhe e cabe na palma branca e dura que me atrela (CESAR, 2013, p. 330).
Publicado postumamente em Antigos e Soltos (2008), "Minuta de férias" é um texto em prosa dividido em duas partes, das quais, por falta de tempo neste momento, só iremos analisar a primeira. 0 texto de frases curtas e protocolares, consoantes com a linguagem sumária e burocrática das minutas, apresenta de início um descompasso - no poema narrado todo no presente da enunciação, o sujeito conta que tem as mãos (ambas!) fraturadas, o que evidencia um deslocamento e uma duplicidade temporal entre o momento da experiência e a escrita. Lembrando a poesia de Armando Freitas Filho, o sujeito com as mãos fraturadas se torna disfuncional - "piora essa pessoa", diz, brincando também com a referência aos outros Pessoas que discutia antes com "ele" - e não consegue contar (talvez no duplo significado de "contar" o triângulo: numericamente ou narrar o seu acontecimento), a memória está atada, não pode "atirar a flauta seca ao mar" (em uma referência direta à Fábula de Anfion, poema de João Cabral de Melo Neto)... Mas, o que mais nos interessa nesse momento é a impossibilidade da escrita que acarreta o diálogo: "Faz vinte dias não olho no espelho" me diz ela. "Faz vinte dias não escrevo palavra" digo-lhe em revide. Estaríamos a falar da mesma coisa?" A relação que se traça aqui é sutil, mas evidente:

Se nos recordarmos bem, Jacques Lacan dizia que o estágio do espelho é o processo durante o qual a criança se depara com o seu próprio reflexo e, progressivamente, em um primeiro momento o confunde com a realidade, percebe se tratar de uma imagem e finalmente compreende que a imagem é um reflexo seu, em um fenômeno que se desenvolve "como uma identificação no sentido pleno que a análise atribui a esse termo, ou seja, a transformação produzida no sujeito quando ele assume uma imagem" (LACAN, 1998, p. 97), reconstruindo a partir de uma referência externa e imaginária a unidade de seu corpo, antes mesmo de conquistar o seu domínio "real" e motor. 0 ato de se olhar no espelho, como "ela" do poema não faz há vinte dias, referiria a um movimento de reconstruir, de novo e de novo, a unidade do próprio corpo que, apesar de sensível, só pode ser verificada visual e simbolicamente a partir da referência da objetividade externa do reflexo.

Se acredita falar da mesma coisa quando equipara ao olhar no espelho o escrever palavra, o sujeito do poema assume similaridades complexas entre o gesto e o processo da constituição da identidade física, corpórea, e lírica: se "ela" verifica a sua unidade diante do espelho, o "eu" verifica e constrói a sua através do ato de escrever; se "ela" constrói o seu corpo simbólico no ato de transformar-se em 
imagem exterior e refletida, o "eu" depende das mãos que possam escrever e, assim, constituir o espaço ficcional específico onde a enunciação pode se realizar:

É pelo corpo que o sujeito se comunica com a carne do mundo, abraçando-a e sendo por ela abraçado. Ele abre um horizonte que engloba e o ultrapassa. Ele é, simultaneamente, vidente e visível, sujeito de sua visão e sujeito à visão do outro, corpo próprio e, entretanto, impróprio, participando de uma complexa intercorporeidade que fundamenta a intersubjetividade que se desdobra na palavra, que é, para Merleau-Ponty, ela mesma, um gesto do corpo. 0 sujeito não pode se exprimir senão através dessa carne sutil que é a linguagem, doadora de corpo a seu pensamento, mas que permanece um corpo estrangeiro (COLLOT, 2007, p. 167).

Assim, chegamos a um ponto de possível conclusão. Neste breve estudo procuramos compreender como os gestos produtivos - o ato da escrita e o ato fotográfico -, uma vez evidentes na superfície dos textos e incorporados como temas, funcionam de maneira a adensar o caráter ficcional e construído destas duas obras supostamente autobiográficas e autorrepresentativas. Estas duas artistas, Ana Cristina Cesar e Vivian Maier, cujas biografias, de fato, não se cruzam, avizinham-se quanto aos gêneros, temas e mecanismos que operam para a construção de seus textos e imagens: desde a escolha pela escrita de diários, correspondências íntimas e autorretratos, passando pela insistência em tornar evidente os limites dos gêneros e os seus graus de ficcionalidade, até a maneira como se utilizam da própria lógica interna dos textos e imagens - como o fotografar-se fotografando e escrever que escreve - para criar procedimentos estéticos poderosos para a sua própria desconstrução.

\section{Referências}

BANNOS, Pamela. Vivian Maier: A Photographer's Life and Afterlife. Chicago: University Of Chicago Press, 2017. https://doi.org/10.7208/chicago/9780226470894.001.0001

BARTHES, Roland. A câmara clara: nota sobre a fotografia. Lisboa: Edições 70, 2014.

BLANCHOT, Maurice. O espaço literário. Rio de Janeiro: Rocco, 2011.
BOSI, Viviana. Ana Cristina Cesar: Não, a poesia não pode esperar. In: BOSI, Viviana.; FALEIROS, Álvaro; ZULAR, Roberto. Sereia de Papel. Visões de Ana Cristina Cesar. Rio de Janeiro: Eduerj, 2015. p. 11-54

BOSI, Viviana. À mercê do impossível. In: CESAR, Ana Cristina. Poética. São Paulo: Companhia das Letras, 2013. p. 425-431.

CAMARGO, Maria Lucia de Barros. Atrás dos olhos pardos: uma leitura da poesia de Ana Cristina Cesar. Chapecó: Argos, 2003

CESAR, Ana Cristina. Poética. São Paulo: Companhia das Letras, 2013.

CESAR, Ana Cristina. Crítica de Tradução. São Paulo: IMS/ Ática, 1999.

CHACAL. Belvedere. São Paulo: Cosac Naify, 2007

COLLOT, Michel. 0 sujeito lírico fora de si. Trad. Alberto Pucheu. Terceira Margem, Rio de Janeiro, Ano IX, n. 11, p. $165-177,2004$.

DUBOIS, Philippe. O ato fotográfico. Campinas: Papirus, 1993,

FABRIS, Annateresa. Identidades virtuais: uma leitura do retrato fotográfico. Belo Horizonte, Ed. UFMG, 2004

FREITAS FILHO, Armando. Poesia, vírgula, viva. In: NOVAES, Adauto (org.). Anos 70: ainda sob a tempestade. Rio de Janeiro: Aeroplano e Senac Rio, 2005.

FOUCAULT, Michel. As Palavras e as Coisas. São Paulo: Martins Fontes, 2007.

HALL, JAMES. The Self-Portrait: a cultural history. Londres: Thames \& Hudson, 2014

HOLLANDA, Heloísa Buarque. Impressões de Viagem. Rio de Janeiro: Aeroplano, 2004.

LACAN, Jacques. $O$ seminário: livro 11 - os quatros conceitos fundamentais da psicanálise. Rio de Janeiro: Jorge Zahar, 1998.

LEMINSKI, Paulo. Toda Poesia. São Paulo: Companhia das Letras, 2013.

LEONI, Luciana. Ana C.: as tramas da consagração. Rio de Janeiro: 7Letras, 2008.

MALUFE, Annita Costa. Ana Cristina Cesar: o poema-corpo ou o poema voltado para fora de si. In: BOSI, Viviana; NUERNBERGER, Renan. Neste Instante. São Paulo: Humanitas, 2018. p. 431-446

MAINGUENEAU, Dominique. O Contexto da obra literária. SP: Martins Fontes, 2001. 
MEDEIROS, Margarida. Fotografia e Narcisismo. Lisboa: Assírio \& Alvim, 2000.

NAVAS, Adolfo M. Fotografia e Poesia (afinidades eletivas). São Paulo: Ubu, 2017.

PAZ, Octavio. Signos em Rotação. São Paulo: Perspectiva, 2012.

PAZ, Octavio. Filhos do Barro. São Paulo: Cosac Naify: 2013.

REINHARD, Kenneth. Kant with Sade, Lacan with Levinas. Modern Languages Notes, v. 110, n. 4, p. 785-808, set. 1995. https://doi.org/10.1353/mln.1995.0077

SANTIAGO, Silviano. Singular e Anônimo. In: CESAR, Ana Cristina. Poética. São Paulo: Companhia das Letras, 2013. p. 452-463.

SISCAR, Marcos. Ana Cristina Cesar. Coleção Ciranda da Poesia. Rio de Janeiro: EdUERJ, 2011. SONTAG, Susan. Sobre Fotografia. São Paulo: Companhia das Letras, 2010.

SOLOMON-GODEAU, Abigail. Photography after Photography. Durham: Duke University Press, 2017. https://doi.org/10.1215/9780822373629

SÜSSEKIND, F. Literatura e vida literária: polêmicas, diários e retratos. Belo Horizonte, Editora UFMG, 2004.

THE VIVIAN MAIER FOUNDATION. Disponível em: www.vivianmaier.com. Acesso em: 19 jun. 2019 .

ZULAR, Roberto. Sereia de papel (algumas anotações sobre a escrita e a voz em Ana Cristina Cesar). In: BOSI, Viviana; FALEIROS, Álvaro; ZULAR, Roberto. Sereia de Papel. Visões de Ana Cristina Cesar. Rio de Janeiro: Eduerj, 2015. p. 81-102.

FINDING Vivian Maier. Direção: John Maloof e Charlie Siskel. Chicago: Ravine Pictures, 2014. 1 DVD (124 min.) DVD Ntsc, son., color. Legendado. Port.

MAIER, Vivian. Self-Portrait, 1955. VM1955W03420-05-MC. Disponível em: http://www. vivianmaier.com/gallery/self-portraits/\#slide-13. Acesso em: 19 jun. 2019.

MAIER, Vivian. Self-Portrait, 1971. VM1971WO1758-10-MC. Disponível em: http://www.vivianmaier. com/gallery/self-portraits/\#slide-37. Acesso em: 19 jun. 2019.

MAIER, Vivian. Self-Portrait, Undated VM19XXW03129-02-MC. Disponível em: http://www. vivianmaier.com/gallery/self-portraits/\#slide-22. Acesso em: 19 jun. 2019.
MAIER, Vivian. 1976. VM1976Ko4621-06-MC. Disponível em: http://www.vivianmaier.com/ gallery/self-portraits-color/\#slide-7. Acesso em: 19 jun. 2019. 